\title{
In vitro and in vivo evaluation of tubulin inhibitors with non-small cell lung cancer pre-clinical models
}

Rati Lama', Danting Liu ${ }^{1}$, Bo Zhong ${ }^{1}$, David Danielpour ${ }^{3}$, Aimin Zhou ${ }^{1,2}$ and Bin Su ${ }^{1,2, *}$

${ }^{1}$ Department of Chemistry, College of Sciences \& Health Professions, Cleveland State University, 2121 Euclid Ave., Cleveland, OH, 44115, USA

${ }^{2}$ Center for Gene Regulation in Health and Disease, College of Sciences \& Health Professions, Cleveland State University, 2121 Euclid Ave., Cleveland, OH, 44115, USA

${ }^{3}$ Division of General Medical Sciences-Oncology and Department of Pharmacology, Case Western Reserve University School of Medicine, 2103 Cornell Road, Cleveland, Ohio 44106, USA

\begin{abstract}
Synthetic small molecule tubulin inhibitors have many advantages as novel anti-cancer agents compared to the current tubulin inhibitors generated from natural products. Our previous studies led to the design and synthesis of a series of novel tubulin inhibitors. Some of these compounds also inhibited heat shock protein 27 (Hsp27), and showed promising in vitro anti-cancer activities in several breast cancer cell lines at sub nano-molar concentrations. However, whether these compounds could suppress tumor growth in animals was not investigated yet. In the current study, to identify the best drug candidates, therapeutic efficacy of the representative compounds from previous analyses was evaluated using non-small cell lung cancer preclinical models. These agents dose-dependently inhibited the growth of lung cancer cells in both monolayer cultures and three-dimensional multicellular spheroids. Several compounds also showed promising tumor growth suppressive activity in nude mice xenograft model.
\end{abstract}

Keywords: tubulin; Hsp27; spheroid; xenograft

\section{Introduction}

Tubulin-containing structures are important for many cellular functions, including chromosome segregation during cell division, intracellular transport, development and maintenance of cell shape, cell motility, and distribution of molecules on cell membranes [1]. Tubulin inhibitors are classical cancer chemotherapeutic agents, well documented to cause cell cycle arrest and induce apoptosis. The most well-known tubulin targeting agent taxol binds to the $\beta$-tubulin sub-unit, disrupts microtubules, arrests cells at the G2/M checkpoint, prevents cell division, and ultimately triggers apoptosis [2,3]. Currently, taxol is used as a first line chemotherapeutic agent for metastatic breast cancer, ovarian cancer, lung cancer, head and neck cancer, and advanced forms of Kaposi's sarcoma. Although treatment with taxol has improved the duration and quality of life for cancer patients, majority of them eventually develop progressive disease after their initial response to the drug. Drug resistance represents a major obstacle for improving the long-term response and survival of cancer patients [4]. Several potential mechanisms have been proposed to account for the resistance to taxol observed in human tumors and tumor cell lines. These mechanisms include over-expression of the multidrug transporter P-glycoprotein, altered metabolism of the drug, decreased sensitivity to death-inducing stimuli, changes in microtubule dynamics due to over-expression of kinestin and altered binding of taxol to microtubules [4-8]. Other FDA approved tubulin inhibitors with complex structures including epothilones analogs and vinca alkaloids analogs have similar drawbacks as taxol. Synthetic small molecule tubulin inhibitors that are not substrates of P-glycoprotein would strongly increase treatment efficacy of a number of malignancies. These agents could also potentially overcome taxol resistance caused by rapid taxol metabolism, P-glycoprotein excretion, and altered taxol tubulin binding. The advantages of synthetic small molecule tubulin inhibitors over tubulin inhibitors derived from natural products, make them attractive anti-cancer agents.

\footnotetext{
*Corresponding author: Bin Su, Ph.D., Department of Chemistry, College of Sciences \& Health Professions, Cleveland State University, 2121 Euclid Ave., Cleveland, OH 44115, USA. Tel.: 216-687-9219; Fax: 216-687-9298; Email: b.su@csuohio.edu

Received 20 March 2015 Revised 17 April 2015 Accepted 22 April 2015 Published 29 April 2015

Citation: Lama R, Liu D, Zhong B, Danielpour D, Zhou A, Su B. In vitro and in vivo evaluation of tubulin inhibitors with non-small cell lung cancer preclinical models. J Cancer Res Ther. 2015; 3(4):44-51. DOI: 10.14312/20524994.2015-6

Copyright: ( 2015 Lama R, et al. Published by NobleResearch Publishers. This is an open-access article distributed under the terms of the Creative Commons Attribution License, which permits unrestricted use, distribution and reproduction in any medium, provided the original author and source are credited.
} 
Heat shock proteins (Hsp) have been shown to be significantly elevated in cancers, and have been associated with cancer progression and drug resistance [9-11]. A small (27 kDa) member of this family, Hsp27, is well established to be particularly adept at protecting cancer cells from various anti-cancer therapeutic agents [12]. Such protection is conferred by enhanced proliferation $[11,13]$ and suppressed apoptosis in cancer cells [14-16]. Increased expression of Hsp27 is found in various cancer types [9, 10, 17-21], supporting the hypothesis that Hsp27 is a therapeutic target in a broad spectrum of cancers. In fact, several agents that modulate Hsp27 have already exhibited promising anti-tumor activity in preclinical models of a variety of tumors, particularly those expressing high levels of Hsp27 [17, 22, 23].

Previously we developed a series of novel anti-cancer agents [24-26]. Some of these agents interfere with tubulin and Hsp27 to suppress proliferation of cancer cells. These dual inhibitors represent a class of new agents that can block two anti-cancer targets [24-26]. They showed different selectivity on inhibiting tubulin polymerization and Hsp27 chaperone function, however decreased cancer cell proliferation with $\mathrm{IC}_{50} \mathrm{~S}$ around sub nano-molar level. It is difficult to identify the best drug candidates from the compound pool for further drug development based only on their cytotoxicity in monolayer cell proliferation assays. Herein, we used two-dimensional (2D) monolayer cell proliferation assay, three-dimensional (3D) multicellular spheroid model and in vivo xenograft to evaluate the representative drug candidates, and identified the most promising drug candidate. All these assays were based on non-small cell lung cancer cell line H292 [27] and the in vivo toxicity of these compounds was determined in mice.

\section{Methods and materials}

\section{Chemicals, regents and cell line}

The sulfonamide tubulin and Hsp27 inhibitors 1 to 8 were synthesized in our lab previously $[24,26]$. Matrigel Matrix was purchased from BD Biosciences (San Jose, CA). 3-(4,5dimethylthiazol-2-yl)-2,5-diphenyl-2H-tetrazolium bromide (MTT) was from Sigma-Aldrich (Milwaukee, WI). H292 lung cancer cells were obtained from ATCC (Rockville, MD). The cells were maintained in RPMI-1640 medium supplemented with 10\% fetal bovine serum (FBS), 2 mmol/L L-Glutamine, and $100 \mathrm{U} / \mathrm{mL}$ penicillin-streptomycin. FBS was heat inactivated for $30 \mathrm{~min}$ in a $56^{\circ} \mathrm{C}$ water bath before use. Cell cultures were grown at $37^{\circ} \mathrm{C}$, in a humidified atmosphere of $5 \% \mathrm{CO}_{2}$ in a Hereaus $\mathrm{CO}_{2}$ incubator.

\section{Cell viability analysis}

The effects of the tubulin inhibitors on $\mathrm{H} 292$ cell proliferation in the 2D monolayer culture were assessed using MTT assay in four replicates. 3,000 cells per well were seeded using RPMI1640 medium in 96-well, flatbottomed plates for $24 \mathrm{~h}$, and were exposed to various concentrations of tubulin inhibitors dissolved in DMSO (final concentration $\leq 0.1 \%$ ) in medium for $72 \mathrm{~h}$. Controls received DMSO vehicle at a concentration equal to that in drug-treated cells. The medium was removed, replaced by $200 \mu \mathrm{l}$ of $0.5 \mathrm{mg} / \mathrm{ml}$ of MTT reagent in fresh medium, and cells were incubated in the $\mathrm{CO}_{2}$ incubator at $37^{\circ} \mathrm{C}$ for $2 \mathrm{~h}$. Supernatants were removed from the wells, and the reduced MTT dye was solubilized in $200 \mu \mathrm{l} /$ well DMSO. Absorbance was determined at $570 \mathrm{~nm}$ on a plate reader.

\section{D multicellular spheroid formation and drug treatment}

Uniform single-spheroid H292 lung carcinoma cells were cultured as follows. The 96-well flat-bottom plates were coated with $70 \mu \mathrm{L}$ of a $1.5 \%$ agarose (weight/volume) solution in distilled water (freshly autoclaved). During the coating process, the agarose solution was maintained at $\geq 60^{\circ} \mathrm{C}$ followed by cooling and setting at room temperature for $40 \mathrm{Min}$. Then the cells were plated at a density of 15,000 cells/well in $80 \mu \mathrm{L}$ of RPMI-1640 (10\% FBS), and allowed to form spheroid in $48 \mathrm{~h}$. The spheroids were then treated with $20 \mu \mathrm{L}$ of a $25 \%$ solution of growth factor-reduced Matrige ${ }^{\mathrm{TM}}$ in cell culture medium [28], resulting in a final volume of $100 \mu \mathrm{L}$ with $5 \%$ Matrigel. Spheroids were cultured for one more day to reach an average diameter of $100 \mu \mathrm{m}$ under standard tissue culture conditions $\left(37^{\circ} \mathrm{C}, 5 \% \mathrm{CO}_{2}\right)$. For drug treatment, $100 \mu \mathrm{L}$ fresh medium with various concentration of drugs were added at day 3 (final Matrigel concentration became $2.5 \%$ after the drug was added). Spheroid morphological images in 96-well microplate were carried out manually on an inverted VWR VistaVision microscope (Bridgeport NJ) equipped with VWR VistaVision camera DV-2D. Spheroid diameters and volumes were determined from their images. The treatment was quart replicated, and the spheroid images were taken every other day. The suppression of the spheroid growth was normalized with control treatment (0.1\% DMSO) [29].

\section{Hsp27 expression determination with Western blot}

H292 monolayer cells and 3D spheroids were lysed, briefly sonicated, and centrifuged at $16000 \mathrm{~g}$ for 30 Min $30 \mu \mathrm{g}$ of protein for each sample was boiled with $2 \mathrm{x}$ loading buffer for 5 Min, electrophoresed on a 10\% SDSpolyacrylamide gel, and transferred onto polyvinylidene difluoride (PVDF) membrane. The membrane was blocked for $1 \mathrm{~h}$ with 5\% nonfat milk in PBST and then incubated with specific Hsp27 primary antibody (Cell Signaling). After washing, the membrane was incubated with horseradishconjugated secondary antibody (Cell Signaling). The bands were visualized by chemiluminescence with ECL reagent (Thermo Scientific).

\section{In vivo xenograft studies}

Five- to six-week-old BALB/c nu/nu, athymic mice were purchased from Taconic labs (Hudson, NY). Sub confluent H292 cells were harvested from monolayer culture and resuspended in an equal volume of Matrigel (BD Biosciences, San Jose, CA) to a final concentration of $1 \times 10^{7} / 0.2 \mathrm{~mL}$. At 8 weeks of age, each animal received S.c. inoculations in two sites per flank with $200 \mu \mathrm{L}$ of $\mathrm{H} 292$ cell suspension. 24 animals were randomly grouped into 8 groups ( 3 mice 
per group). Tumors were measured twice weekly with calipers, and tumor volume was calculated by the following formula: (width) ${ }^{2} \times$ length/2. Treatments began when the tumors reached a measurable size $\left(\sim 200 \mathrm{~mm}^{3}\right)$. Treated group was intraperitoneal administrated $10 \mathrm{mg} / \mathrm{kg} / \mathrm{d}$ of corresponding drugs three times a week (1\%DMSO, $1 \%$ Tween 80 in PBS as vehicle). The control group received the vehicle treatment. Body weights were monitored weekly as an indicator of the animals' overall health. After three weeks of treatment, the mice were euthanized and the tumors were removed, weighed.

\section{Statistical analysis}

Statistical and graphical information was determined using GraphPad Prism software (GraphPad Software Incorporated) and Microsoft Excel (Microsoft Corporation). $\mathrm{IC}_{50}$ values were determined using nonlinear regression analysis.

\section{Results}

Eight compounds inhibited cell proliferation at sub nanomolar concentrations

Non-small cell lung cancer cell line $\mathrm{H} 292$ was used as the preclinical model, due to several factors. First, H292 cells are tumorigenic and can form xenograft tumor in nude mice. Second, H292 exhibited high Hsp27 expression, and the expression is significantly increased in their 3D-multicellar spheroid model (Figure 1). Since several compounds in our previous studies showed Hsp27 inhibition [24, 26], H292 served as a perfect model to accurately determine the therapeutic efficacy of these compounds.

\section{D monolayer 3D spheroid}

\section{HSP27}

$\beta$-actin

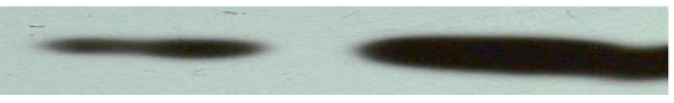

Figure 1 Expression of Hsp27 in monolayer and spheroid of H292 cells. 3D spheroid based on H292 NSCLC cells.

Eight representative compounds from our previous studies were examined in the cell proliferation assay (Figure 2). Compounds 1 and 2 have a 2, 5-dimethyl benzyl moiety, and inhibited the proliferation of $\mathrm{H} 292$ monolayer cells dose-dependently with $\mathrm{IC}_{50} \mathrm{~S}$ of $63 \mathrm{nM}$ and $47 \mathrm{nM}$ respectively (Table 1 ). The results showed that these compounds were less active to inhibit the growth of cancer cells compared to the other six compounds. Compounds 1 and 2 were selected for this study because they inhibited both tubulin polymerization and Hsp27 chaperone functions [24]. However, their potency to inhibit tubulin polymerization was lower than those of the compounds with a 2, 5-dimethoxy benzyl moiety i.e. compounds 3,4,7 and $8[24,26]$. The inhibitory activities of the compounds on the tubulin polymerization and Hsp27 chaperone function are summarized in Table $2[24,26]$. It seems that for compounds 1 and 2, the Hsp27 inhibitory activity did not contribute much to the inhibition of cell proliferation.
(A)

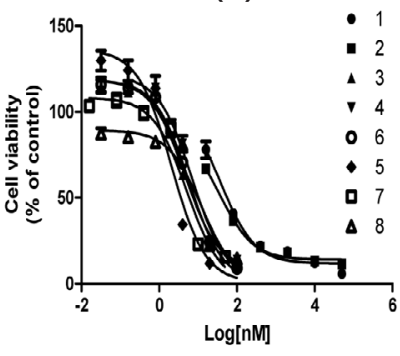

(B)

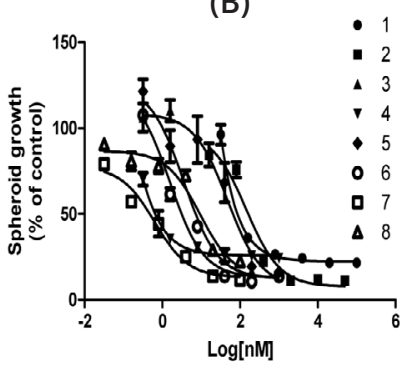

Figure 2 Compounds 1 to 8 dose-dependently inhibited (A) monolayer cell proliferation and (B) spheroid growth.

Their relatively lower tubulin targeting effect could have led to the lower potency to suppress cell growth in the monolayer cell proliferation assay. Compound 3, 4, 5, 6, 7 and 8 with a 2, 5-dimethoxy benzyl moiety exhibited much better potency to inhibit $\mathrm{H} 292$ monolayer cell proliferation with $\mathrm{IC}_{50} \mathrm{~S}$ of $4.4 \mathrm{nM}, 8.3 \mathrm{nM}, 19.8 \mathrm{nM}, 9.6 \mathrm{nM}, 5.4 \mathrm{nM}$, and $13.1 \mathrm{nM}$, respectively. Due to the substitution of 2 , 5-dimethyl benzyl moiety in compounds 1 and 2 with 2, 5-dimethoxy benzyl moiety, the solubility of compounds 3, 4,5 and 6 improved based on their cLogP values. Previous mechanistic studies showed that the 2, 5-dimethoxy benzyl substitution decreased the inhibition of Hsp27 [24]. Compound 4 did not inhibit Hsp27 activity even at $10 \mu \mathrm{M}$ and compound 3 only slightly inhibited Hsp27 at $10 \mu \mathrm{M}$ [24]. However, both compounds showed much better potency to inhibit tubulin polymerization compared to compounds 1 and 2 [24], which could have greatly contributed to their activity against $\mathrm{H} 292$ cell proliferation. Compounds 5 and 6 showed slightly weaker cell growth inhibition compared to compounds 3 and 4, suggesting that the 4-methoxybenzamide and 4-iodobenzamide are preferred substituted groups. Compounds 7 and 8 showed strong cell growth inhibition. They are structurally similar to compound 3 , but the methanesulfonamide moiety is changed to ethanesulfonamide and benzenelsulfonamide, respectively. Both compounds also selectively inhibited tubulin polymerization with similar potency compared to compounds 3 and 4, but showed no Hsp27 inhibition even at $10 \mu \mathrm{M}$ [26]. This further demonstrated that tubulin targeting effects are the main attribution for the inhibition of cancer cell proliferation in monolayer cell culture assays.

The compounds time and dose-dependently inhibited the growth of H292 3D spheroids

Although the compounds effectively inhibited the proliferation of cells grown in monolayer culture assays, the tumor penetration ability of the compounds cannot be predicted with such assays. Herein, we used a threedimensional multicellular tumor spheroid model to select the most promising anti-cancer drug candidates. The results demonstrated that the compounds time and dosedependently inhibited the growth of the 3D spheroids (Figure 2).

The $I C_{50}$ values generated from the $3 D$ spheroid assay are also listed in Table 1. In general, our drug candidates 
Table 1 Animal toxicity, hydrophobicity, and $\mathrm{IC}_{50} \mathrm{~S}$ of inhibition of $\mathrm{H} 292$ lung cancer cell growth with 2D and 3D assays by dual tubulin and Hsp27 inhibitors.

\begin{tabular}{|c|c|c|c|c|c|c|}
\hline & \multirow{2}{*}{$\begin{array}{l}\text { Compound } \\
\text { Structures }\end{array}$} & \multirow{2}{*}{$\begin{array}{l}2 D \text { cell proliferation } I C_{50} \\
(n M)\end{array}$} & \multirow{2}{*}{$\begin{array}{l}3 D \text { spheroid growth } I C_{50} \\
(n M)\end{array}$} & \multirow{2}{*}{$C \log P$} & \multicolumn{2}{|c|}{ In vivo toxicity } \\
\hline & & & & & $10 \mathrm{mg} / \mathrm{Kg} / 3 i p /$ week & $10 \mathrm{mg} / \mathrm{Kg} / 5 \mathrm{ip} /$ week \\
\hline 1 & & $63.3 \pm 3.3$ & $130 \pm 70$ & 5.50 & - & - \\
\hline 2 & & $46.7 \pm 16.7$ & $170 \pm 50$ & 4.39 & - & - \\
\hline 3 & & $4.4 \pm 0.2$ & $12.7 \pm 4.2$ & 4.56 & - & + \\
\hline 4 & & $8.3 \pm 1.8$ & $0.84 \pm 0.36$ & 3.45 & - & + \\
\hline 5 & & $19.8 \pm 3.4$ & $66.5 \pm 8.1$ & 3.11 & - & - \\
\hline 6 & & $9.6 \pm 2.2$ & $4.8 \pm 1.5$ & 3.42 & - & - \\
\hline 7 & & $5.4 \pm 0.7$ & $0.41 \pm 0.15$ & 5.09 & - & - \\
\hline 8 & & $13.1 \pm 4.2$ & $9.0 \pm 3.1$ & 6.33 & ND & ND \\
\hline
\end{tabular}

Note: $\mathrm{H} 292$ cells were treated at various concentrations of the indicated compounds in quart replicates for 48h (2D assay) and 7days (3D assay). Each test was repeated independently three times and the representative data are listed in the table. CLogP values were generated with ChemDraw 12 . The cell viability in 2D assay was measured with MTT. The spheroid size was calculated based on the diameters of spheroid, and subsequently] normalized to the control to generate the IC50s. Toxicity was evaluated by more than $20 \%$ weight loss.

Table 2 The compounds showed different activities to inhibit tubulin polymerization and Hsp27 chaperone function.

\begin{tabular}{|c|c|c|c|c|c|c|c|c|}
\hline Compound & 1 & 2 & 3 & 4 & 5 & 6 & 7 & 8 \\
\hline Tubulin inhibition at $1 \mu \mathrm{M}$ & $34 \%$ & $25 \%$ & $64 \%$ & $66 \%$ & ND & ND & $59 \%$ & $56 \%$ \\
\hline Hsp27 inhibition at $10 \mu \mathrm{M}$ & $28 \%$ & $30 \%$ & $27 \%$ & $9 \%$ & ND & ND & 0 & 0 \\
\hline
\end{tabular}

showed similar potency trend in the $2 \mathrm{D}$ and $3 \mathrm{D}$ screening assays, suggesting similar capabilities to penetrate the tumor. Both compounds 1 and 2 showed weaker activities in $2 \mathrm{D}$ and $3 \mathrm{D}$ assays compared to other six analogs, with $\mathrm{IC}_{50} \mathrm{~S}$ of $130 \mathrm{nM}$ and $170 \mathrm{nM}$ from the 3D assay, respectively. Hsp27 expression was up regulated in the 3D spheroids (Figure 1). However, compounds 1 and 2 did not exhibit better potency in 3D model even though they inhibited Hsp27 more than other compounds. It is possible that their Hsp27 targeting effect is still not significant enough to contribute to their cell growth inhibition. Compounds 4 and 7 showed the best results in 3D spheroid assay with $I_{50} \mathrm{~S}$ below $1 \mathrm{nM}$, which are lower than the $I C_{50} \mathrm{~S}$ from the 2D assay, suggesting the two compounds have the best cell penetration ability. Both compounds might have higher accumulation in the 3D spheroids after longterm treatment, which can enhance their activity in the 3D assay. But more experiments are needed to confirm this speculation. Compound 3 exhibited a weaker activity with an $\mathrm{IC}_{50}$ of $13 \mathrm{nM}$ compared to 4 and 7 . Even compound 3 showed great potency in the monolayer cell proliferation assay. Nevertheless, all the compounds dose-dependently suppressed the growth of the spheroids, and provided important data to select the best drug candidates. To examine the long-term treatment of these compounds on spheroid growth, the potent compounds $3,4,5,6,7$, and 8 
were further tested with the 3D spheroid assay in a dose and time-dependent manner. The spheroid growth assay was conducted for a period of 10 days and the spheroid size was examined every other day (Figure 3 ). Compounds $3,4,6,7$, and 8 suppressed more than $80 \%$ of the spheroid growth at $40 \mathrm{nM}$. Compound 5 was less potent compared to other analogs, which is also indicated by its higher $I C_{50}$
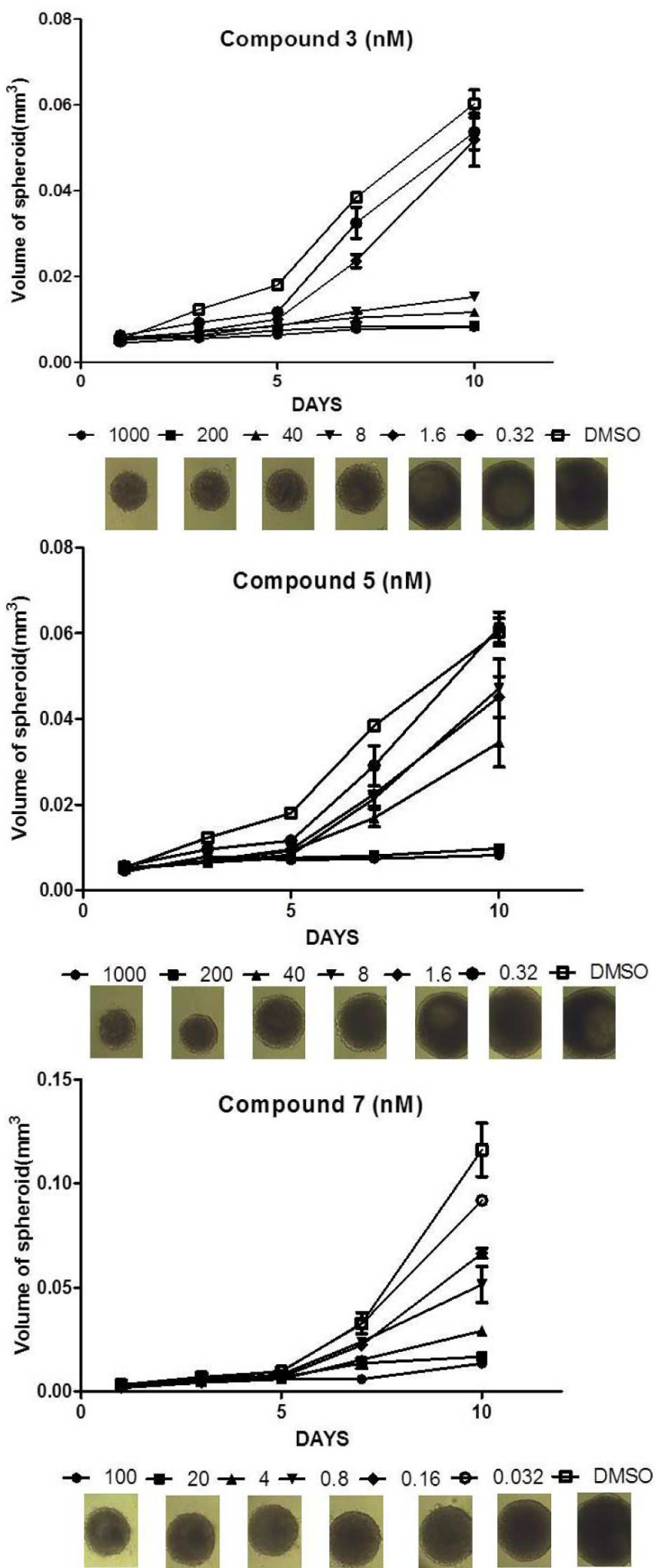

value in the 3D assay. It only inhibited about $40 \%$ spheroid growth at $40 \mathrm{nM}$. Compound 4 showed the best potency, and inhibited about $20 \%$ growth of the spheroid at 0.32 $\mathrm{nM}$. Overall, the tumor penetration capability of these compounds reflects their potential to have strong anticancer activity in vivo.
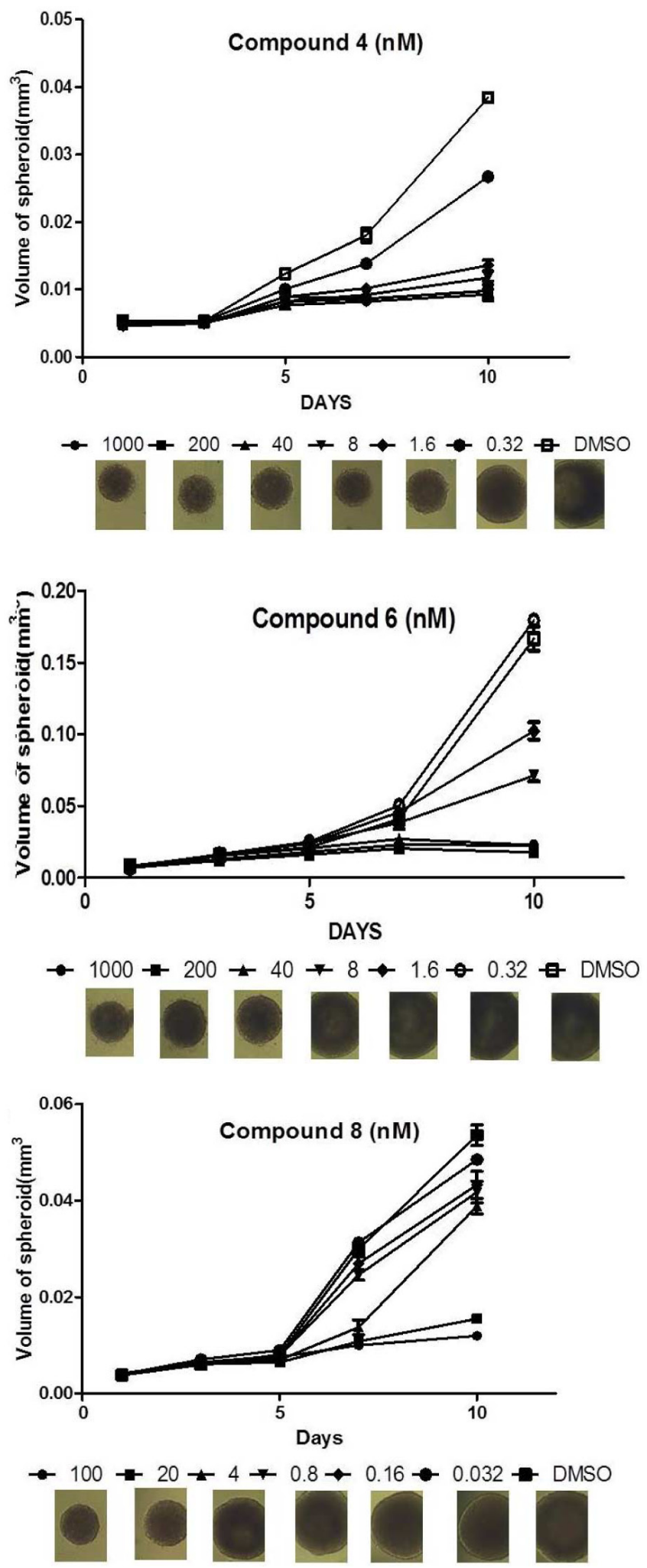

Figure 3 Spheroid growth inhibition curves of compounds 3, 4, 5, 6, 7, and 8. Spheroid morphological images in 96-well microplate were carried out manually on an inverted VWR VistaVision microscope (Bridgeport NJ) equipped with VWR VistaVision camera DV-2D. Spheroid diameters and volumes were determined from their images. The treatments were performed in four replicates, and the spheroid images were taken every other day. 


\section{Toxicity evaluation of the compounds}

Before examining the compounds with the in vivo xenograft model, we tested the toxicity of the compounds in nude mice to determine the maximum tolerable dosages (Table 1). The drugs were formulated with $1 \%$ Tween 80 and administrated via intraperitoneal (ip) injection. Compound 8 has poor water solubility and precipitated significantly when it was formulated with $1 \%$ Tween 80 , which limited its injection and was removed from the test. At $10 \mathrm{mg} / \mathrm{kg}$ (three times per week), none of the drugs caused toxicity to the mice as indicated by no weight loss or dehydration (Table 1). At $10 \mathrm{mg} / \mathrm{kg}$ (five times per week), compounds 3 and 4 caused severe weight loss and dehydration in mice after a week treatment. When we increased the dosage to $15 \mathrm{mg} / \mathrm{kg}$ three times per week and five times per week, compounds 1, 2, 5, 6, and 7 did not cause toxicity. Compounds 3 and 4 were not tested at these dosages. Compound 7 shares a similar structure with compound 3 by having a common 4-iodobenzamide moiety. Apparently, the methanesulfonamide moiety of compound 3 is more toxic compared to ethanesulfonamide moiety in compound 7. This structural characteristic is important information to design less toxic drug candidates in the future. The maximum tolerable dosage was determined to be $10 \mathrm{mg}$ / $\mathrm{kg}$ (three times per week) due to the toxicity of compounds 3 and 4 at higher dosages. The seven compounds were tested at this dosage on $\mathrm{H} 292$ xenograft model in nude mice.

\section{In vivo xenograft study}

After the xenograft reach $200 \mathrm{~mm}^{3}$, the seven compounds were formulated with $1 \%$ Tween 80 in PBS to treat the mice. All the compounds inhibited tumor growth, and no weight loss was observed in nude mice after three weeks treatment (Figure 4). Compound 4 showed the best potency, inhibited about $70 \%$ tumor growth compared to the control group. Compound 3 showed similar tumor suppression activity compared to compound 5, although 3 was much more active than 5 in the $2 \mathrm{D}$ and $3 \mathrm{D}$ assays. It seems that the 3D spheroid assay results cannot accurately mimic the in vivo activity of our compounds. Compounds 1, 2, 6 and 7 exhibited similar tumor growth inhibition as well, which is inconsistent to their significantly different activities in vitro 2D and 3D assays. Particularly, compound 7 showed the best activity in the 3D spheroid assay, but was not very potent in the in vivo test. This discrepancy may be explained by their different metabolic stabilities, serum protein binding affinities and other unknown factors. Further pharmacokinetic studies are needed to elucidate the discrepancy in the potency of these compounds in the 3D assay and in vivo experiment. Obviously, it is difficult to predict the in vivo activity of drug candidates based only on the in vitro assays.
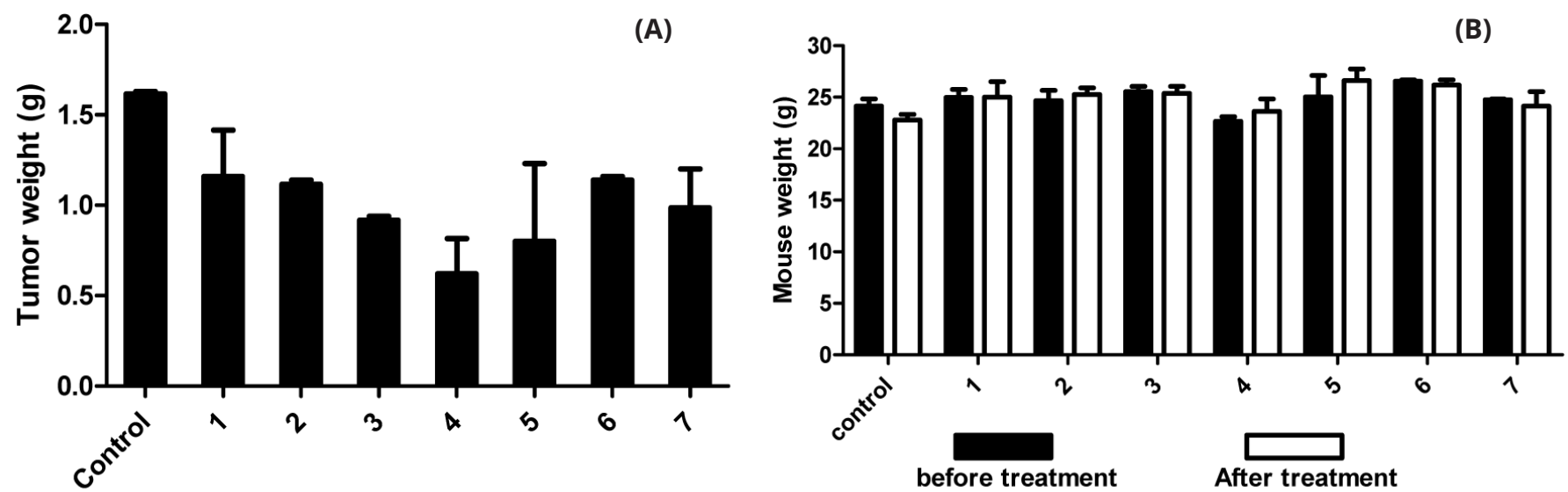

Figure 4 A, B Tumor weights after the treatment of the seven compounds at $10 \mathrm{mg} / \mathrm{Kg} /$ three times per week. After three weeks of treatment, the mice were euthanized and the tumors were removed and weighed.

\section{Discussion}

We used preclinical non-small cell lung cancer models to evaluate the anti-cancer potency of eight synthetic small molecular tubulin inhibitors. All the compounds showed good potency to inhibit the cancer cell proliferation at sub nano-molar concentrations. However, cancer cells growing on 2D plastic surface is an artificial cellular environment and cannot accurately mimic the 3D in vivo tumor environment [30]. These monolayer growing cells lose part of their phenotypic and functional characteristics compared to the cells in the 3D real tumors [31]. Therefore, the drug candidates identified with this assay may not be the best compounds for further in vivo studies. In contrast, 3D multicellular spheroids mimic tumor environment much better. The strong cell-cell interactions in 3D spheroids exhibit great similarity to the cells in real tumor. The pharmacological activity of the anti-cancer drugs in 3D spheroid assay closely mimics the way tumors in vivo respond to chemotherapy. Apparently, the multicellular 3D spheroid culture has multiple advantages over 2D cell culture when selecting the most promising anti-cancer drug candidates from a large pool of compounds. To further narrow down the compound list into the most promising drug candidates, the effects of these tubulin inhibitors were evaluated with a well-validated 3D spheroid assay developed using the $\mathrm{H} 292$ cells [29].

The cancer cell line, H292 proliferates aggressively and expresses high level of Hsp27 protein. Particularly, the Hsp27 expression is increased in the 3D spheroids. However, it seems that the Hsp27 expression did not 
distinguish the compounds tested in the study. The potency of the compounds in both the 2D and 3D assays were dependent mainly on their tubulin targeting effect. There are two possible explanations. First, Hsp27 may not significantly contribute to the proliferation of $\mathrm{H} 292$ cells despite the high expression levels. Therefore the targeting effect of the compounds cannot be reflected in the cell growth assay. Second, the Hsp27 inhibition of these compounds is not potent enough to contribute to the inhibition of cell growth.

Compounds 4 and 7 exhibited the best potency in the 3D spheroid assay with $\mathrm{IC}_{50} \mathrm{~S}$ below $1 \mathrm{nM}$. Particularly, compound 4 inhibited about $20 \%$ growth of the spheroid even at $0.32 \mathrm{nM}$. In the in vivo study, the compound also exhibited the best potency to inhibit the tumor growth. However, compounds that showed great potency in the 2D and 3D assays may not necessarily show good potency in the in vivo animal testing. Many factors such as metabolic stability, solubility, and protein binding affinity may not affect the results in in vitro assay much, but will significantly impact the in vivo activity. For example, compounds 6 and 7 both exhibited $\mathrm{IC}_{50} \mathrm{~S}$ at sub nano-molar levels in the $2 \mathrm{D}$ and $3 \mathrm{D}$ experiments, but were not very potent in the animals.

Overall, most of these tubulin inhibitors suppressed in vitro spheroid and in vivo tumor growth. The structural characteristics of the compounds were correlated to their in vivo potency and toxicity, which shed light on designing more potent and less toxic derivatives in future. It seems that the best drug candidate that showed higher activity in all the assays was compound 4. It exhibited good potency in the $2 \mathrm{D}$ cell proliferation assay with an $\mathrm{IC}_{50}$ of $8.3 \mathrm{nM}$, in the $3 \mathrm{D}$ spheroid assay with an $\mathrm{IC}_{50}$ of $0.84 \mathrm{nM}$ and also inhibited the tumor growth at $10 \mathrm{mg} / \mathrm{kg}$ (three times per week) dosage in mice. However, this compound has a relatively narrow therapeutic index compared to other analogs. Future structural optimization will focus on the improvement of the general toxicity of this compound.

\section{Conclusion}

The combination of $2 \mathrm{D}$ and $3 \mathrm{D}$ cell culture screening methods provide a more accurate strategy to identify the best drug candidates. Overall, the potential drug candidates will show good potency with both the assays as indicated by compound 4. However, compounds that exhibit good potency in both assays may not show the best in vivo activity as indicated by compounds 6 and 7. Nevertheless, it is a good strategy to use the combination of these assays to eliminate less promising drug candidates in anti-cancer drug development processes.

\section{Acknowledgments}

This research was supported by Center for Gene Regulation in Health and Disease (GRHD) of Cleveland State University and Ohio Department of Development (ODOD), and also supported by CSU Dissertation Research Award (DRA).

\section{Conflict of interest}

None of the authors declare any conflict of interest.

\section{References}

[1] Heald R, Nogales E. Microtubule dynamics. J Cell Sci. 2002; 115:3-4.

[2] Ahn HJ, Kim YS, Kim JU, Han SM, Shin JW, et al. Mechanism of taxolinduced apoptosis in human SKOV3 ovarian carcinoma cells. J Cell Biochem. 2004; 91(5):1043-1052.

[3] Das GC, Holiday D, Gallardo R, Haas C. Taxol-induced cell cycle arrest and apoptosis: dose-response relationship in lung cancer cells of different wild-type p53 status and under isogenic condition. Cancer Lett. 2001; 165(2):147-153.

[4] Orr GA, Verdier-Pinard P, McDaid H, Horwitz SB. Mechanisms of Taxol resistance related to microtubules. Oncogene. 2003; 22:7280-7295.

[5] Britten CD, Baker SD, Denis LJ, Johnson T, Drengler R, et al. Oral paclitaxel and concurrent cyclosporin A: targeting clinically relevant systemic exposure to paclitaxel. Clin Cancer Res. 2000; 6(9):34593468 .

[6] De S, Cipriano R, Jackson MW, Stark GR. Overexpression of kinesins mediates docetaxel resistance in breast cancer cells. Cancer Res. 2009; 69(20):8035-8042.

[7] Horwitz SB, Cohen D, Rao S, Ringel I, Shen HJ, et al. Taxol: mechanisms of action and resistance. J Natl Cancer Inst Monogr. 1993; (15):55-61.

[8] Parekh H, Wiesen $\mathrm{K}$, Simpkins $\mathrm{H}$. Acquisition of taxol resistance via P-glycoprotein- and non-P-glycoprotein-mediated mechanisms in human ovarian carcinoma cells. Biochem Pharmacol. 1997; 53(4):461470.

[9] Arts HJ, Hollema H, Lemstra W, Willemse PH, De Vries EG, et al. Heatshock-protein-27 (hsp27) expression in ovarian carcinoma: relation in response to chemotherapy and prognosis. Int J Cancer. 1999; 84(3):234-238.

[10] Garrido C, Mehlen P, Fromentin A, Hammann A, Assem M, et al. Inconstant association between 27-kDa heat-shock protein (Hsp27) content and doxorubicin resistance in human colon cancer cells. The doxorubicin-protecting effect of Hsp27. Eur J Biochem. 1996; 237(3):653-659.

[11] Hsu HS, Lin JH, Huang WC, Hsu TW, Su K, et al. Chemoresistance of lung cancer stemlike cells depends on activation of Hsp27. Cancer. 2011; 117(7):1516-1528.

[12] Garrido C, Brunet M, Didelot C, Zermati Y, Schmitt E, et al. Heat shock proteins 27 and 70: anti-apoptotic proteins with tumorigenic properties. Cell Cycle. 2006; 5(22):2592-2601.

[13] Kamada M, So A, Muramaki M, Rocchi P, Beraldi E, et al. Hsp27 knockdown using nucleotide-based therapies inhibit tumor growth and enhance chemotherapy in human bladder cancer cells. Mol Cancer Ther. 2007; 6(1):299-308.

[14] Garrido C, Solary E. A role of HSPs in apoptosis through "protein triage"?. Cell Death Differ. 2003; 10(6):619-620.

[15] Garrido C, Bruey JM, Fromentin A, Hammann A, Arrigo AP, et al. HSP27 inhibits cytochrome c-dependent activation of procaspase-9. FASEB J. 1999; 13(14):2061-2070.

[16] Concannon CG, Gorman AM, Samali A. On the role of Hsp27 in regulating apoptosis. Apoptosis. 2003; 8(1):61-70.

[17] Baylot V, Andrieu C, Katsogiannou M, Taieb D, Garcia S, et al. OGX-427 inhibits tumor progression and enhances gemcitabine chemotherapy in pancreatic cancer. Cell Death Dis. 2011; 2:e221.

[18] Elpek GO, Karaveli S, Simşek T, Keles N, Aksoy NH. Expression of heatshock proteins hsp27, hsp70 and hsp90 in malignant epithelial tumour of the ovaries. APMIS. 2003; 111(4):523-530.

[19] Kang SH, Kang KW, Kim KH, Kwon B, Kim SK, et al. Upregulated HSP27 in human breast cancer cells reduces Herceptin susceptibility by increasing Her2 protein stability. BMC Cancer. 2008; 8:286.

[20] Langer R, Ott K, Specht K, Becker K, Lordick F, et al. Protein expression profiling in esophageal adenocarcinoma patients indicates association of heat-shock protein 27 expression and chemotherapy response. Clin Cancer Res. 2008; 14(24):8279-8287.

[21] Sherman M, Multhoff G. Heat shock proteins in cancer. Ann N Y Acad Sci. 2007; 1113:192-201. 
[22] Heinrich JC, Tuukkanen A, Schroeder M, Fahrig T, Fahrig R. RP101 (brivudine) binds to heat shock protein HSP27 (HSPB1) and enhances survival in animals and pancreatic cancer patients. J Cancer Res Clin Oncol. 2011; 137(9):1349-1361.

[23] Chauhan D, Li G, Shringarpure R, Podar K, Ohtake Y, et al. Blockade of Hsp27 overcomes Bortezomib/proteasome inhibitor PS-341 resistance in lymphoma cells. Cancer Res. 2003; 63(19):6174-6177.

[24] Zhong B, Chennamaneni S, Lama R, YiX, Geldenhuys W], et al. Synthesis and anticancer mechanism investigation of dual Hsp27 and tubulin inhibitors. J Med Chem. 2013; 56(13):5306-5320.

[25] Zhong B, Cai X, Chennamaneni S, Yi X, Liu L, et al. From COX-2 inhibitor nimesulide to potent anti-cancer agent: synthesis, in vitro, in vivo and pharmacokinetic evaluation. Eur J Med Chem. 2012; 47(1):432-444.

[26] Zhong B, Lama R, Kulman DG, Li B, Su B. Lead optimization of dual tubulin and Hsp27 inhibitors. Eur J Med Chem. 2014; 80:243-253.

[27] Lama R, Zhang L, Naim JM, Williams J, Zhou A, et al. Development, validation and pilot screening of an in vitro multi-cellular threedimensional cancer spheroid assay for anti-cancer drug testing. Bioorg Med Chem. 2013; 21(4):922-931.

[28] Li Q, Chen C, Kapadia A, Zhou Q, Harper MK, et al. 3D models of epithelial-mesenchymal transition in breast cancer metastasis: highthroughput screening assay development, validation, and pilot screen. J Biomol Screen. 2011; 16(2):141-154.

[29] Lama R, Zhang L, Naim JM, Williams J, Zhou A, et al. Development, validation and pilot screening of an in vitro multi-cellular threedimensional cancer spheroid assay for anti-cancer drug testing. Bioorg Med Chem. 2013; 21(4):922-931.

[30] Pampaloni F, Reynaud EG, Stelzer EH. The third dimension bridges the gap between cell culture and live tissue. Nat Rev Mol Cell Biol. 2007; $8(10): 839-845$.

[31] Djordjevic B, Lange CS. Cell-cell interactions in spheroids maintained in suspension. Acta Oncol. 2006; 45(4):412-420. 